\title{
The BIOCEM Project: The Industrial Valorization of a Patent Through the "Proof of Concept" Program
}

\author{
Tiziana Cardinale ${ }^{*}$, Corradino Sposato ${ }^{1}$, Maria Bruna Alba ${ }^{1}$, Andrea Feo $^{1}$, Giorgio Leter ${ }^{2}$, Piero De Fazio ${ }^{1}$ \\ ${ }^{1}$ TERIN-SAEN Centro Ricerche ENEA Trisaia, Rotondella (MT) 70026, Italy \\ ${ }^{2}$ SSPT - TECS - SAM Centro Ricerche ENEA Casaccia, Roma 00123, Italy
}

Corresponding Author Email: tizcardina@ hotmail.it

https://doi.org/10.18280/ijdne.150607

Received: 28 June 2020

Accepted: 8 October 2020

\section{Keywords:}

$A A C$, thermal performance, lightweight material, eco-friendly, porosity, energy optimization, sustainability

\begin{abstract}
The aim of BIO-CEM project is focused to test an innovative patented concrete aeration system in scale-up pre-industial production of aerated autoclaved concrete blocks. The aeration system refers to the Bio-Aerated Autoclavated Concrete (BAAC) international patent $n^{\circ} 102017000101039$ - WO/2019/049005, developed by the ENEA researchers. This activity research is included in the "Proof of Concept Program" granted by ENEA (Italian National Agency for New Technologies, Energy and Sustainable Economic Development) in 2018, aiming to reduce the gap between research results and industrial application. The targets of BAAC innovation are addressed to energy saving, $\mathrm{CO}_{2}$ reduction and environmental sustainability, obtained also by complete recycling of waste materials. In this regard, preliminary experiments were conducted in laboratory to test different types of mix design for the optimization of quality parameters such as: mechanical strength, thermal insulation and environmental impact. These tests are the first step of the industrial scale up, made in partnership with EKORU srl that has contributed with its own expertise and industrial plant facility.
\end{abstract}

\section{INTRODUCTION}

ENEA's PoC (Proof of Concept) Fund is a tool that aims to reduce the gap between research results and industrial application. In order to support the development of technologies with a low degree of technological maturity and to promote technology transfer to industry, short-term financial resources are made available to carry out experiments that demonstrate the feasibility of a technology or product concept: (a) build/improve a prototype to prepare it for commercialization; (b) verify commercial feasibility or scale up testing; (c) demonstrate risk mitigation for a potential investor/industry or licensee, if a patent exists; (d) address and overcome a specific gap identified by the industry and which hinders its attractiveness to investors.

The BIO-CEM project is part of this operational context and aims to create some prototypes of autoclaved aerated concrete (AAC) for the building market, innovative in terms of energy saving and environmental sustainability.

Conventional AAC is produced from a mixture of Portland cement, lime, water, gypsum and sand $[1,2]$. To these reagents is added metallic aluminum powder whose reaction with calcium hydroxide determines the formation of hydrogen, responsible for the reduction of density in the final product [3]. The final maturation process takes place inside autoclaves operating at temperatures between $160^{\circ} \mathrm{C}$ and $200^{\circ} \mathrm{C}$ which will determine the final consolidation and increase the mechanical properties $[4,5]$. A wide range of densities (300$1800 \mathrm{~kg} / \mathrm{m}^{3}$ ) can be obtained thereby offering flexibility in manufacturing products for specific applications (structural, partition and insulation grades) [6].

The BIOCEM project is based on the patent filed in 2017 by ENEA researchers, in which the innovation is in the aeration process and in the mix design of the components that make up the product defined Bio-Aerated Auto clavated Concrete (BAAC).

The innovation mainly consists of the technology used to make the aerating agent and in particular of the use of microorganisms (yeasts) that together with hydrogen peroxide generate the oxygen necessary for the formation of porosity and the reduction of block density. The system was tested in the laboratory and proved to be advantageous in terms of costeffectiveness, physical and mechanical performance.

\section{THE BIO-AERATED AUTOCLAVED CONCRETE}

In aerated concrete, the method of pore-formation influences the microstructure and determines its physical and mechanical properties [7]. The material structure of aerated concrete is characterized by the microporous and macropores matrix. The macropores are formed due to the expansion of the mass caused by aeration and the micropores appear in the walls between the macropores [8].

The commercial auto clavated aerated concrete (AAC) is a prefabricated cementitious material used in the building industry, consisting of a mixture of Portland cement, lime, gypsum, metallic aluminum powder, water, silica sand powder with the addition of aerating agents such as aluminum metal powder that reacts chemically with the lime releasing molecular hydrogen $\left(\mathrm{H}_{2}\right)$, responsible for the porous structure of the AAC.

The action of the aerating medium produces an increase in the volume of the material from 1.5 to 5 times than the original 
volume of the cement [9]. The leavening process stops when the material reaches a given solid consistency: the voids stabilize in the volume of material and the contained hydrogen is gradually released into the atmosphere and afterward replaced by air.

Despite the described process is largely used in AAC production nonetheless there are some critical aspects to be takes in account, first of all using of aluminium powder which can react with the oxygen presents in the air at room temperature: the smaller its particles (less than $100 \mu \mathrm{m}$ ), the greater the risk of explosion or fire. These powders are rarely uniform, since it is very likely to find aluminium particles of a size considered "safe" mixed with particles smaller than 100 $\mu \mathrm{m}$. As a result, a possible risk of explosion is achieved together with a high combustion speed.

The search for an alternative aerating agent $[10,11]$ that avoids these issues is therefore of high relevance for the producers who, moreover, could also reduce the safety-related costs. The innovation introduced by the BAAC method could be the real alternative to the traditional one in order to removes inherent safety risk in production procedures and in reduction of related cost in provision for safety at work.

A fundamental and characterizing aspect of the BAAC patent is the replacement of the conventional aerating medium (aluminium powder) with an enzymatic dismutation of the hydrogen peroxide. The enzyme catalase, present in almost living organisms [12], in presence of hydrogen peroxide leads to the dismutation reaction producing molecular oxygen and water. In BAAC aeration process, the yeast Saccharomyces cerevisiae was used thanks to its high content in catalase. The yeast Saccharomyces cerevisiae cell (generally called brewer's yeast) is added to cement, fine siliceous sand, water and hydrogen peroxide to perform the BAAC mix design.

Once the catalase enzyme makes the breakdown reaction of hydrogen peroxide inside the cement mortar, the released oxygen will form the porosities increasing the volume of the cementitious mass with the consequent reduction of the final density of the product. The real innovation of the BAAC patent is that the aeration reaction takes place independently of the presence of other chemical components in the mixture.
Initially, based on previous experience [13], laboratory reference samples were packaged, according to the formulation of the conventional aerated product with aluminium powder. Subsequently [14] specimens were made with the BAAC method in order to compare the physical and mechanical properties achieved by the two manufacturing processes (Figure 1).

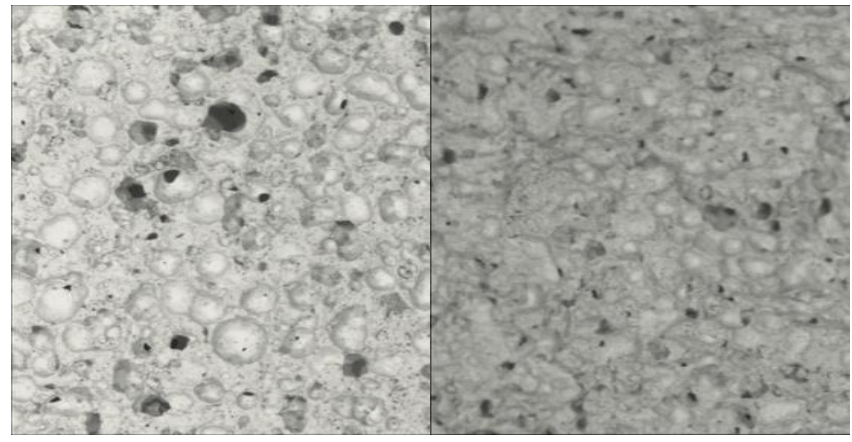

Figure 1. Comparison of the dimensions and the distribution of porosity between the BAAC test specimen (left) and the commercial AAC specimen (right) observed by Olympus optical microscope mod. SZ 40 (10x)

As a further improvement of the mix design has been also tested a solid form of peroxide in place of the liquid one, useful to formulate some dry pre-mixed products with the purpose to facilitate the pre-fabricated blocks production steps and make it also possible other building application made in situ.

\section{MATERIALS AND METHODS}

Some tests were carried out in the ENEA's laboratories of Trisaia Research Centre in order to define the mix design with the best qualities of density parameters, thermal conductivity and compressive strength (Table 1).

Table 1. Components of BAAC mix design

\begin{tabular}{cc}
\hline Components & Characteristics \\
\hline Sand & Quartz 99.2\% purity $\left(0.45 \%\right.$ of $\left.\mathrm{Al}_{2} \mathrm{O}_{3}\right)$, average diameter smaller than $10 \mu \mathrm{m}$ (Silverbond SA600, Sibelco Italia) \\
Anhydrous silica sand: 90\% average diameter smaller than $90 \mu \mathrm{m}$ (EKORU) & CEM IIA-LL 42,5R Portland (Italcementi) \\
Cement & CEM IIA-LL 42,5R Portland (Calme-Speziali) \\
Water & Tap water \\
Yeast & Freeze-dried yeast (Pedon) \\
Hydrogen peroxide & 130 volumes in water solution \\
Sodium percarbonate & (A. Sella s.r.l. pharmaceutical chemical lab) \\
& Pure in granules Active Oxygen $\geq 13.0 \%$ \\
(Farmalabor)
\end{tabular}

The sand has been kindly supplied by EKORU s.r.l., partner of BIO-CEM project. This type of aggregate is coarser than Silverbond SA600 and represents the standard of industrial silica aggregate.

As regards the use of cement for the production of autoclaved aerated concrete [15], the most used type from the industrial point of view is CEM II A/LL $42.5 \mathrm{R}$. This cement represents the best component for autoclaved concrete products.

CEM II A/LL $42.5 \mathrm{R}$ is a composite Portland cement, with a percentage of clinker between 80 and $94 \%$, an amount of limestone between 6 and 20\%, secondary constituents between 0 and 5\%, mechanical strength at 28 days equal to or greater than $42.5 \mathrm{MPa}$ for compressive strength by using standard sand.

Using of hydrogen peroxide or sodium percarbonate entails a different way of preparing the samples, justifying the two methodologies illustrated below.

Method for preparing specimens using hydrogen peroxide $(\operatorname{method} A)$ : 
(1) Sand and cement are placed in an appropriate container and dry mixed for 1 minute;

(2) Yeast was dissolved in water at a temperature of $40^{\circ} \mathrm{C}$ and further mixed for about 1 minute;

(3) The mixture containing yeast is gradually added to the solid mixture and the resulting grout is mixed by hand for 3 minutes;

(4) Further mixing of the grout by an electric mixer for a total time of 5 minutes;

(5) $\mathrm{H}_{2} \mathrm{O}_{2}$ is added by a graduated pipette and mixed by hand for 30 seconds;

(6) The resulting grout is placed inside the mould, where it remains for 3 hours at room temperature for leavening and completion of the setting phase. In this passage, cubic geometry formwork was used containing $0.5 \mathrm{~kg}$ of dry weight of the solid materials composing the grout.

The dismutation reaction of the $\mathrm{H}_{2} \mathrm{O}_{2}$ present in the grout takes place at room temperature and is completed within 1520 minutes after the addition of $\mathrm{H}_{2} \mathrm{O}_{2}$ with a consequent volume increase of the grout of about $80 \%$ if compared to the initial one.

Method for preparing specimens using sodium percarbonate (method B):

(1) All solids (sand, cement, yeast and sodium percarbonate) are placed in an appropriate container and mixed dry for 1 minutes;

(2) Water at room temperature is gradually added to the solid mixture and the resulting grout is continuously mixed by hand for 1 minutes;

(3) Further mixing of the grout takes place with an electric impeller for a time equal to 2 minutes.

(4) The mixture is transferred to the mould where it remains for 3 hours at room temperature to complete the setting phase. In this phase, formworks of cubic geometry $(10 \times 10 \times 10 \mathrm{~cm})$ were used.

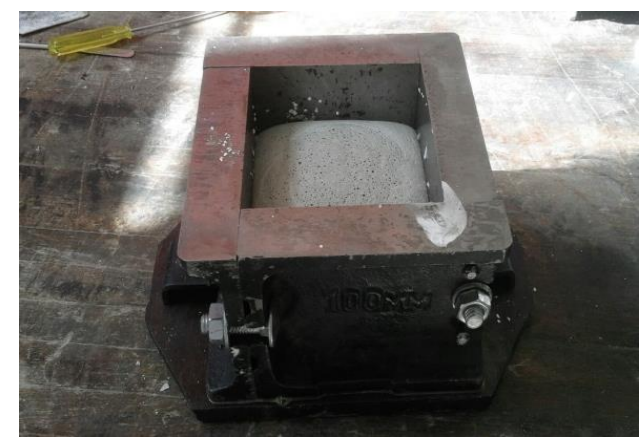

Figure 2. Specimen before leaving phase

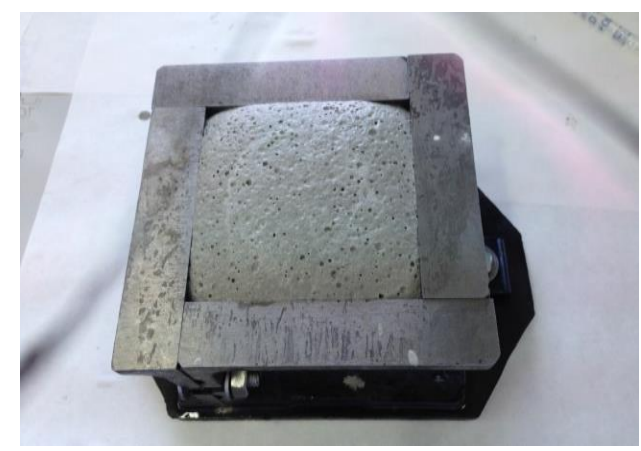

Figure 3. Specimen after leaving phase with the typical convex shape ("panettone" type)

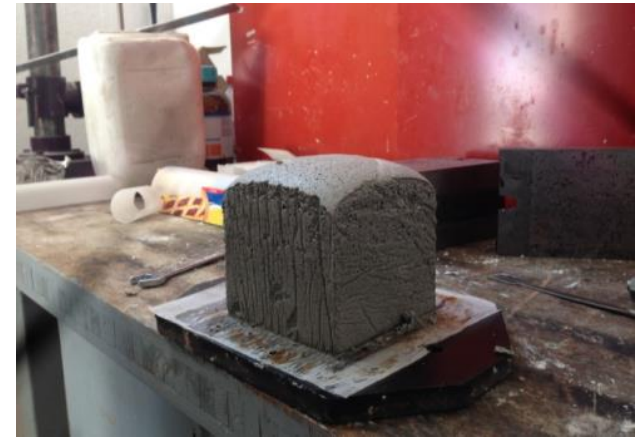

Figure 4. Specimen after removal from the formwork

All the reagents were used as received with the exception of yeast and sodium percarbonate for which a particle size reduction was carried out by means of a vibrating disc mill (Retsch RS 200); 2 min at $1000 \mathrm{rpm}$ were sufficient to obtain a fine powder of a size comparable to concrete.

Once the setting phase is complete, the final steps of the procedures are common to the two methodologies A/B (Figure 2, Figure 3). At this point, the specimen takes on a consistency that can be removed from the formwork. The operation must be done carefully to avoid cracks inside the material (Figure 4).

The specimen is then placed in an autoclave (Figure 5) at a temperature of $190^{\circ} \mathrm{C}$ under saturated steam conditions for a total of 12 hours $[16,17]$. Once the period in the autoclave is completed (Figure 6), the specimen is left in the oven to dry for $24-48 \mathrm{~h}$ at a temperature of $110^{\circ} \mathrm{C}$.

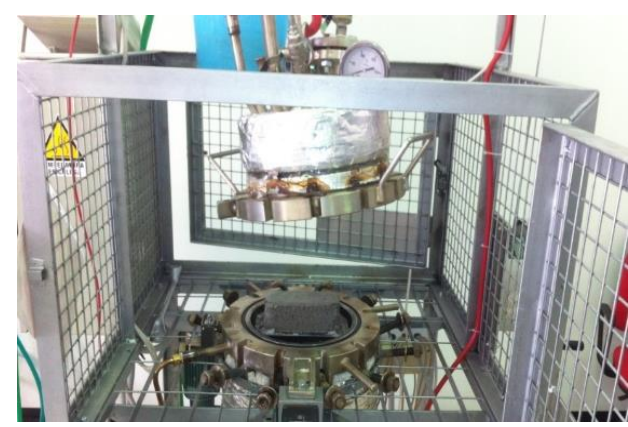

Figure 5. Laboratory hand - made autoclave

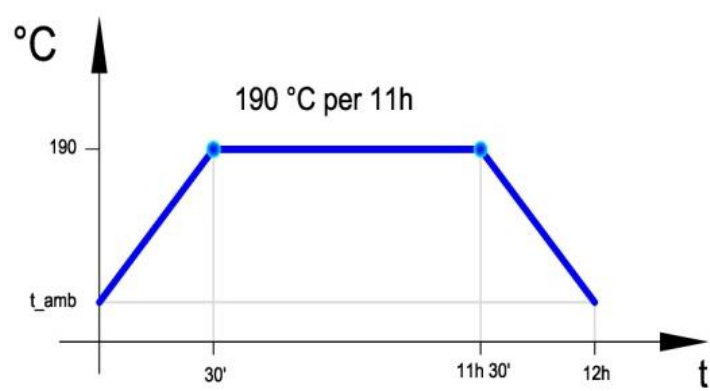

Figure 6. Autoclave process

After 24 hours it has been verified that the weight was stabilized and then it was possible to characterize BAAC specimens according to the UNI standard for autoclaved aerated concrete, in order to evaluate the following physical parameters:

(1) Dimensions according to UNI EN 772-16: 2011 [18] "Method for determining the overall dimensions";

(2) Density according to UNI EN 678: 1994 [19] "Procedure for defining the dry density"; 
(3) Compressive strength (ratio between the breaking load under axial compression and the surface of the specimen section perpendicular to the direction of the compressive load) according to UNI EN 679: 2005 [20] "Determination of the compressive strength of autoclaved aerated concrete";

(4) Thermal conductivity by heat flow meter Netzsch HFM436/3 according to UNI EN ISO 12664:2002 [21] "Thermal performances of building materials and productsDetermination of thermal resistance by means of guarded hot plate and heat flow meter methods - Dry and moist products of medium and low thermal resistance". The standard is applied to specimens having a thermal resistance not less than 0.1 $\mathrm{m}^{2} \mathrm{~K} / \mathrm{W}$ and a thermal conductivity no greater than $2.0 \mathrm{~W} / \mathrm{mK}$ ). Also, UNI EN 1745:2020 [22] "Determination of thermal properties of masonry units and masonry" was followed: the standard provides the rules for determining the dry thermal and design values of thermal conductivity of masonry and masonry products.

Standards provide for a set of at least three test specimens, taken, when possible, one in the lower third, one in the central third and one in the upper third of the element, with reference to the direction of expansion of the mixture. In the specific case, for the reasons linked to the reduced size of the instrumentation and the mixtures, only one specimen was taken with a height depending on the size of the formwork.

The specimens were cut from the mixture with a band saw, since the execution of the tests requires that the surfaces must not show flatness deviations greater than $0.1 \mathrm{~mm}$; where possible, they have been rectified. The final specimens are cubes with the side of $100 \mathrm{~mm}$. After rectification, the specimens were kept at a temperature of $110^{\circ} \mathrm{C}$ until they reached a moisture content equal to $6( \pm 2) \%$ of the mass, then they were kept for two hours at the test room temperature (airconditioned room at $20 \pm 5^{\circ} \mathrm{C}$ and $\mathrm{RH} 50 \%$ ).

The compression test was performed according to the UNI 679: 2005 standard [20]: the standard specifies the procedure for determining the compressive strength of autoclaved aerated concrete and supports the product standards on precast components of autoclaved aerated concrete.

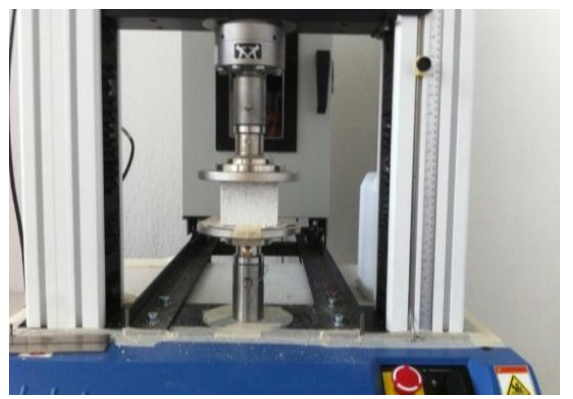

Figure 7. Instron 3369 dual column test apparatus

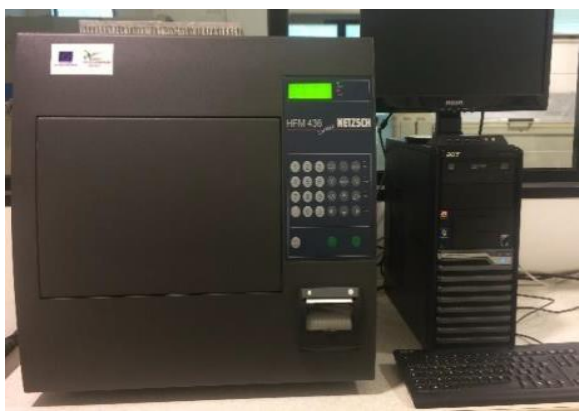

Figure 8. Heat flow meter Netzsch HFM436/3
An Instron 3369 double column universal machine with a load cell of $50 \mathrm{kN}$ and a maximum speed of $2 \mathrm{~mm} / \mathrm{min}$ was used for the test (Figure 7).

Considering the size of the used autoclave, cubic specimens were prepared directly and placed in the autoclave for a maximum of three at a time. Before the test the specimens were centred, with accuracy, on the lower plate. The compressive strength was determined as the ratio between the breaking load in axial compression and the cross-sectional area of the test sample perpendicular to the direction of casting. When the specimen breaking occurs the maximum load value was recorded.

The device used for thermal conductivity measurements is a heat flow meter (Figure 8) placed in a laboratory conditioned at a temperature of $23 \pm 2{ }^{\circ} \mathrm{C}$ and relative humidity $50 \pm 5 \%$, to ensure compliance with the conditions required by the UNI EN standard 12664: 2002 [21].

\section{RESULTS AND DISCUSSION}

\subsection{Evaluation of the type of cement on BAAC products}

In order to study the effect of different kinds of cement on the production of BAAC specimens, preliminary feasibility tests were carried out using cement of the same type from 2 brands:

- Italcementi CEM II A/LL $42.5 \mathrm{R}$

- Calme Speziali CEM II A/LL 42.5 R

As highlighted above, although cement with a different brand has the same characteristics according to the UNI 197/1 standard [23], the effect on the production of BAAC specimens is different. This probably depends in particular to the amount of clinker (80-94\%) and fillers (6-20\%) in Portland cement which, in addition to being variable in discrete quantities, could affects the aeration process as well as the final density of the product.

To this end, a series of specimens were prepared with a standardized recipe to evaluate the specific effect of the type of cement. The following Table 2 shows the recipe for making the specimens.

Table 2. Standard mix design for cements evaluation

\begin{tabular}{cc}
\hline Components & Amount \\
\hline Sand & $300[\mathrm{~g}]$ \\
Cement & $200[\mathrm{~g}]$ \\
Water & $350[\mathrm{~g}]$ \\
Yeast & $2.5[\mathrm{~g}]$ \\
Hydrogen peroxide & $6.5[\mathrm{ml}]$ \\
\hline
\end{tabular}

The sand used for the mix design reported in Table 2 is Silverbond SA600.

The samples produced were made in standard 10x10x10 cm moulds. To assess the influence of cement, the following parameters were monitored:

- heights of the product;

- density (expressed in $\mathrm{kg} / \mathrm{m}^{3}$ );

- mechanical strength (expressed in $\mathrm{MPa}$ );

- $\quad$ percentage increase in volume.

The height of the grout inside the mould was determined both in the contact surface with the mould and in the central surface, before the addition of $\mathrm{H}_{2} \mathrm{O}_{2}$ and at the end of the leavening process, as indicated below: 
(1) Initial height (H1) on the wall before the addition of $\mathrm{H}_{2} \mathrm{O}_{2}$;

(2) Final height $(\mathrm{H} 2)$ on the wall and at the end of the leavening;

(3) Final height (H3) evaluated at the center at the end of the reaction.

The variation in height increase of the specimen is always greater at the centre than at the wall of the mold (Figure 9).

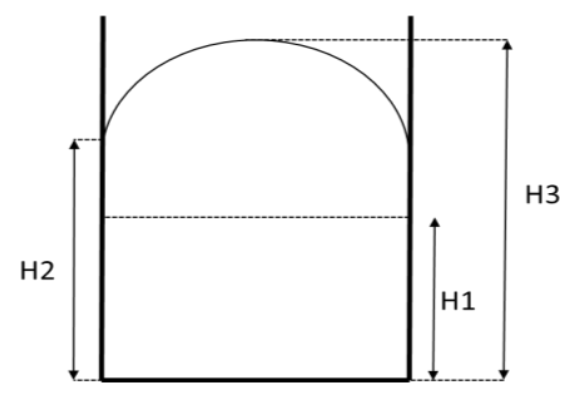

Figure 9. Graphic representation of the specimen

It has also been observed that, during the leavening phase, the free surface of the specimens (the upper part) has a convex shape ("panettone" type), presumably due to the friction exerted by the walls of the mold on the cement grout, in function of the viscosity of the mix, of the anisotropy of the cement-wall contact area and of the size of the free surface area.

The Table 3 shows the type of cement, the heights of the specimens (H1 is equal to $48 \mathrm{~mm}$ for both of them), the density [19], the mechanical compressive strength [20]. The height percentage increase, calculated as $(\mathrm{H} 3-\mathrm{H} 1) / \mathrm{H} 3$, respectively equal to $52 \%$ (Italcementi) and $56.4 \%$ (Calme-Speziali). The obtained results show that, all other boundary conditions being equal, the specimens made with Calme-Speziali cement has greater growth, highlighted by both the H3 height and the density. This implies that, in order to obtain a product at a target density, a smaller quantity of aerating agent (hydrogen peroxide) is required, which is also the reagent with the highest added value.

Table 3. Physical and mechanical results related to the different brands

\begin{tabular}{ccccc}
\hline Cement & $\begin{array}{c}\text { H2 } \\
{[\mathbf{m m}]}\end{array}$ & $\begin{array}{c}\mathbf{H 3} \\
{[\mathbf{m m}]}\end{array}$ & $\begin{array}{c}\text { Density } \\
{\left[\mathbf{k g} / \mathbf{m}^{3}\right]}\end{array}$ & $\begin{array}{c}\text { Compressive } \\
\text { strength [MPa }]\end{array}$ \\
\hline Italcementi & 92 & 100 & $500-550$ & $3-3.5$ \\
CalmeSpeziali & 100 & 110 & $450-500$ & $2.9-3.3$ \\
\hline
\end{tabular}

Both the cement types present substantially the same overall response in term of density and compressive strength.

Furthermore, with Calme-Speziali cement it was also possible to develop a mix design to reach the target density of $300 \mathrm{~kg} / \mathrm{m}^{3}$ by re-modulating the yeast/hydrogen peroxide ratio. The data are shown in the table below (Table 4).

Table 4. BAAC mix design with Calme-Speziali cement with a density of $350 \mathrm{~kg} / \mathrm{m}^{3}$

\begin{tabular}{cc}
\hline Components & Amount \\
\hline Sand & $300[\mathrm{~g}]$ \\
Cement & $200[\mathrm{~g}]$ \\
Water & $350[\mathrm{~g}]$ \\
Yeast & $1[\mathrm{~g}]$ \\
Hydrogen peroxide & $14.1[\mathrm{ml}]$ \\
\hline
\end{tabular}

The higher amount of hydrogen peroxide is necessary to produce a greater volume increase than previously made specimens. To prevent the grout from leaking out of the formwork, the value of $3 / 5$ was used as the basis for calculating the quantity of reagents used for the recipe.

The mechanical strength is equal to $1.4 \mathrm{MPa}$, substantially similar to autoclaved aerated concrete products, usually used for thermal and acoustic insulation of buildings.

\subsection{Evaluation of yeast amount on BAAC products}

In order to study the different densities of BAAC specimens and identify the best types and weight ratios of raw materials, an experimental study was implemented to evaluate the influence of yeast on the aeration process. In this regard, using the standard recipe shown in Table 2, different amount of yeast was added to the mixture.

The sand used for mix design reported in Table 2 is Silverbond SA600.

Table 5 shows the heights of the specimens made with variable quantities of yeast in the range $0-2.5 \mathrm{~g}$. The $\mathrm{H} 1$ value (48 mm), starting point of the growth, the same for each specimen, represents the height of the grout before the introduction of hydrogen peroxide and is the temporal beginning of the aeration process.

Figure 10 shows the trend of the height $\mathrm{H} 3(\mathrm{~mm})$, of the samples made with the standard recipe as the amount of yeast varies.

With the standard recipe, and in particular with a constant amount of hydrogen peroxide equal to $6.5 \mathrm{ml}$, the variation in the yeast quantity with respect to the growth of the specimens shows an increasing trend up to $1.5 \mathrm{~g}$ of yeast content, after which, increasing value, the growth remains constant.

This means that the dismutation reaction of hydrogen peroxide is the limiting factor affecting the growth, whereas the yeast content is related to the number of reactions site occurred inside the sample that generate the amount of porosity. At this regard a right ratio between peroxide and yeast is necessary to get the required density with an optimum pores distribution.

Table 5. Variation in heights of samples Vs quantity of yeast

\begin{tabular}{ccc}
\hline Yeast & H2 $[\mathbf{m m}]$ & H3 $[\mathbf{m m}]$ \\
\hline 2.5 & 100 & 110 \\
2 & 93 & 108 \\
1.5 & 95 & 108 \\
1 & 85 & 97 \\
0.5 & 80 & 94 \\
0 & 70 & 87 \\
\hline
\end{tabular}

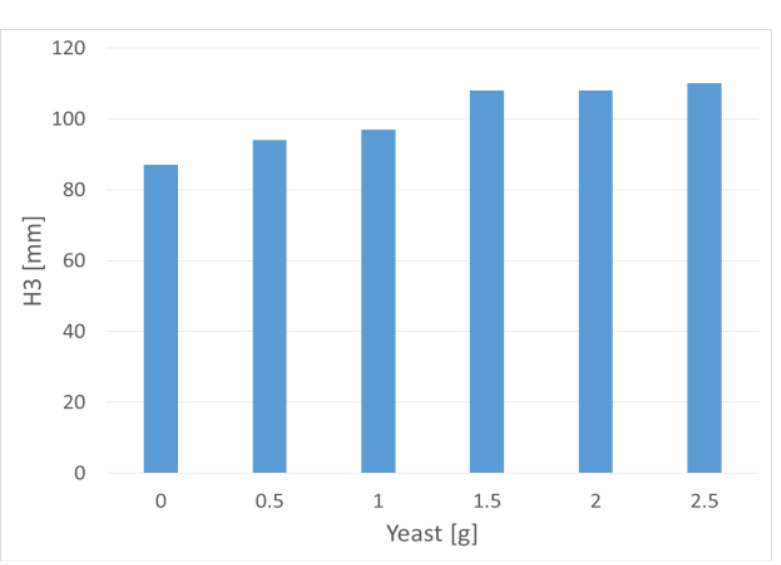

Figure 10. Height trend of the sample Vs the yeast amount 


\subsection{Performance analysis of sodium percarbonate}

Once verified the feasibility, further experimental tests have been carried out to understand the behaviour of BAAC specimens prepared with sodium percarbonate compared with the ones aerated with hydrogen peroxide.

The sand used for mix design reported in Table 6 is EKORU type.

The produced specimens (Table 7) show a very good reproducibility of results with an average density of $543 \mathrm{~kg} / \mathrm{m}^{3}$ and a compressive strength of $3.72 \mathrm{MPa}$. The standard deviation of these two parameters is respectively $18 \mathrm{~kg} / \mathrm{m}^{3}$ and $0.86 \mathrm{MPa}$ [15].

Table 6. Standard mix design for BAAC specimens made with sodium percarbonate

\begin{tabular}{cc}
\hline Components & Amount \\
\hline Sand & $300[\mathrm{~g}]$ \\
Cement & $200[\mathrm{~g}]$ \\
Water & $350[\mathrm{~g}]$ \\
Yeast & $2.5[\mathrm{~g}]$ \\
Sodium percarbonate & $10[\mathrm{~g}]$ \\
\hline
\end{tabular}

Table 7. Physical parameters of BAAC samples made with sodium percarbonate

\begin{tabular}{ccc}
\hline Specimen & $\begin{array}{c}\text { Density } \\
{\left[\mathbf{k g} / \mathbf{m}^{\mathbf{3}}\right]}\end{array}$ & $\begin{array}{c}\text { Compressive strength } \\
{[\mathbf{M P a}]}\end{array}$ \\
\hline P1 & 520 & 2.76 \\
P2 & 525 & 3.4 \\
P3 & 530 & 3 \\
P4 & 548 & 4.7 \\
P5 & 550 & 3.4 \\
P6 & 563 & 3.7 \\
P7 & 567 & 5.1 \\
Average & 543 & 3.72 \\
Standard deviation & 18 & 0.86 \\
\hline
\end{tabular}

This recipe was further validated through the preparation of

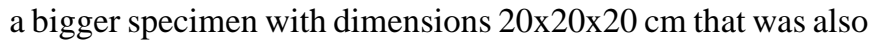
useful to fix thermal conductivity $\lambda$, measured to $0.118 \mathrm{~W} / \mathrm{mK}$, in good agreement with the specimens previously made with hydrogen peroxide and with the commercial product as well.

Heat transfer through porous materials is affected by conduction, and at high temperatures, by radiation. The homogeneous character of the material and its low thermal conductivity and diffusivity suggest that cellular concretes might possess excellent fire resistance properties and hence its use does not involve any risk of spread of flames [6].

Fire resistance properties are superior to those of ordinary dense concrete where the presence of coarse aggregate leads to differential rates of expansion, cracking and disintegration.

This type of product, due its chemical composition, is considered Euroclass A1 material [24] for fire reaction.

\section{CONCLUSIONS}

This paper describes the experimental activity carried out at the laboratories of ENEA Trisaia DTE-SAEN and ENEA Casaccia SSPT-TECS-SAM aimed at testing some innovative modifications in the manufacturing process of autoclaved aerated concrete, according to the international ENEA patent n¹02017000101039 - WO/2019/049005, called BAAC.
Essentially the BAAC innovation can be included inside the bio inspired technology solutions; in fact, in nature, the same mechanism is used by an insect family, the Brachiniane Bonelli, 1810 or commonly called Bombardier Beetles who mix, inside a special organ, hydrogen peroxide and catalase to achieve an explosive reaction used as defence mechanism when they are attacked, allowing them time to escape.

In the described innovative process of cement aeration, the catalase, a biochemical enzyme delivered by yeast cells, promotes the breakdown reaction of the hydrogen peroxide and the release of molecular oxygen causing a porous structure and a cement density reduction. The process obtained through the organic aeration medium represents a valid alternative to the conventional process, first of all thanks to the elimination of aluminium powder that is highly advantageous in terms of safety and environmental impact [25]. Infact, aluminum production is highly energy-intensive and geopolitically dependent, in fact in the last twenty years despite the fact that global aluminium production is substantially constant, most of the production has polarized in the Asian region with China in a strategic position.

Another advantage in terms of costs and sustainability of the production process is related to the leavening phase: in the case of BAAC it occurs at room temperature, instead for commercial AAC it is necessary to maintain the grout at a controlled temperature variable between $40^{\circ} \mathrm{C}$ and $80^{\circ} \mathrm{C}$ for the whole leavening process.

Experimental tests were performed to demonstrate the feasibility of the use of sodium percarbonate instead of hydrogen peroxide, in order to make even easier, faster and safer the BAAC manufacturing process. It comes in a powder form, on solid base. The eco-friendly molecule decomposes after use into water, oxygen and soda ash, resulting in minimal impact on the environment as the harmless elements disappear in nature. So, it can combine the properties of the hydrogen peroxide with a greater manageability and safety in the various work phases.

The goal is to create a pre-mixed high-performance cement mix to which only water is added, with positive consequences both in economic and environmental terms.

In conclusion, on the basis of the results obtained, the innovative patented process for the realization of BAAC appears to be advantageous with respect to the conventional production process of the commercial typology. Its unique aspect, due to the ability of allow the aeration through an autonomous agent, give to BAAC a wide potentiality in new construction materials project.

Experiments are still in progress and are focused on the optimization of physical, thermal and mechanical behaviour of the cementitious material, in order to enhance all the aspects connected to economic sustainability principles, environment impact reduction, building comfort and construction safety.

\section{ACKNOWLEDGMENT}

The authors thank Mr Claudio Bacchi (CEO fo EKORU s.r.1.) and Eng. Alfredo Casillo (director of the EKORU production plant located in Volla) for their indispensable support in BIOCEM project and Dr. Enrico Sopini (SIBELCO Italia S.p.A.) for providing the silica sand. 


\section{REFERENCES}

[1] Vats, F. (2019). Autoclaved aerated concrete: Versatile building material. International Journal of Advance Research, Ideas and Innovation in Technology, 5(3): 2092-2098.

[2] Hellers Bo, G., Schmidt Bo, R. (2011). Autoclaved Aerated Concrete (AAC)-the story of a low-weight material. Materials of 5th International Conference on Autoclaved Aerated Concrete-Securing sustainable future, Bydgoszcz, Poland, pp. 63-68.

[3] Saiyed, F.M., Makwana, A.H., Pitroda, J., Vyas, C.M. (2014). Aerated Autoclaved Concrete (AAC) blocks: Novel material for construction industry. International Journal of Advanced Research in Engineering, Science \& Management, I(II): 21-32.

[4] Aidan, A., Shareefdeen, Z., Bogdanov, B., Markovska, I., Rusev, D., Hristov, Y., Georgiev, D. (2009). Preparation and properties of porous aerated concrete. Materials Science, 48(9): 24-28.

[5] Tanaçan, L., Ersoy, H.Y., Arpacioglu, U. (2009). Effect of high temperature and cooling conditions on aerated concrete properties. Construction and Building Materials, 23(3):

$1240-1248$

https://doi.org/10.1016/j.conbuildmat.2008.08.007

[6] Keyvani, A. (2014). Thermal performance \& fire resistance of autoclaved aerated concrete exposed humidity conditions. IJRET: International Journal of Research in Engineering and Technology, 3(3): 267-272.

[7] Narayanan, N., Ramamurthy, K. (2000). Structure and properties of aerated concrete: A review. Cement \& Concrete Composite, 22(5): 321-329. https://doi.org/10.1016/S0958-9465(00)00016-0

[8] Schober, G. (2011). Porosity in autoclaved aerated concrete (AAC): A review on pore structure, types of porosity, measurement methods and effects of porosity on properties. CWB-Special Issue, 39-43.

[9] Struhárová, A., Rouseková, I. (2007). Porous structure of cellular concrete and its impact on selected physicalmechanical properties of cellular concrete. Slovak Journal of Civil Engineering, 2: 35-43.

[10] Van Boggelen, D.R. (2011). Safe aluminium dosing in AAC plants. Aircrete Europe B.V., Oldenzaal, The Netherlands, 45-50.

[11] Tang, V.L., Vu, K.D., Hro, C.X., Tho, D.V. (2019). Effect of aluminium powder on light-weight aerated concrete properties. E3S Web of Conferences, 97(2): 10. https://doi.org/10.1051/e3sconf/20199702005

[12] Chelikani, P., Ramana, T., Radhakrishnan, T.M. (2005). A Repertoire of unusual features. Indian Journal of
Clinical Biochemustry, 20(2): 131-135. https://doi.org/10.1007/BF02867412

[13] Alba, M.B., Cardinale, T., De Fazio, P., Lista, G.F., Sposato, C. (2016). Tests for the characterization of fiber reinforced autoclaved aerated concrete. ECCM17 - 17th European Conference on Composite Materials Munich, Germany, pp. 1-8.

[14] Cardinale, T., Sposato, C., Alba, M.B., Feo, A., Leter, G., De Fazio, P. (2020). Bio-aerated autoclaved concrete: A new solution for a sustainable product in the building sector. TECNICA ITALIANA-Italian Journal of Engineering Science, 64(2-4): 341-346. https://doi.org/10.18280/ti-ijes.642-432

[15] UNI EN 771-4:2015. Elementi di calcestruzzo aerato autoclavato per muratura.

[16] Ekaputri, J.J., Triwulan, T., Brahmantyo, D., Nasir, S., Raja, F. (2013). Optimization of pressure and curing time in producing autoclaved aerated concrete. 6th Civil Engineering Conference in Asia Region: Embracing the Future trough Sustainability, pp. 50-56. https://doi.org/10.13140/2.1.2505.6964

[17] Bisceglie, F., Gigante, E., Bergonzoni, M. (2014). Utilization of waste autoclaved aerated concrete as lighting material in the structure of a green roof. Construction Building Materials, 69: 351-361. https://doi.org/10.1016/j.conbuildmat.2014.07.083

[18] UNI EN 772-16:2011. Metodi di prova per elementi per muratura - Parte 16: Determinazione delle dimensioni.

[19] UNI EN 678-1994. Calcestruzzo aerato autoclavato (AAC). Determinazione della massa volumica a secco.

[20] UNI EN 679-2005. Determinazione della resistenza a compressione del calcestruzzo aerato autoclavato.

[21] UNI EN 12664:2002. Thermal performance of building and products - Determination of thermal resistance by means of guarded hot plate and heat flow meter methods - Dry and moist products of medium and low thermal resistance.

[22] UNI EN 1745:2020. Determination of thermal properties of masonry units and masonry.

[23] UNI EN 197-1: 2011 - Cemento - Parte 1: Composizione, specificazioni e criteri di conformità per cementi comuni.

[24] UNI EN 13501-1:2019 Classificazione al fuoco dei prodotti e degli elementi da costruzione - Parte 1: Classificazione in base ai risultati delle prove di reazione al fuoco.

[25] Rathi, S.O., Khandve, P.V. (2016). Cost effectiveness of using AAC blocks for building construction in residential building and public buildings. IJRET: International Journal of Research in Engineering and Technology, 5(5): 517-520. 